\title{
Youth vaping: a review and update on global epidemiology, physical and behavioral health risks, and clinical considerations
}

\author{
Timothy D. Becker ${ }^{1}$ (D) $\cdot$ Timothy R. Rice ${ }^{1}$ (D)
}

Received: 8 March 2021 / Revised: 24 May 2021 / Accepted: 21 July 2021 / Published online: 15 August 2021

(c) The Author(s), under exclusive licence to Springer-Verlag GmbH Germany, part of Springer Nature 2021

\begin{abstract}
Worldwide, youth electronic cigarette use (vaping) has risen significantly over the past decade. This public health concern has spurred many high-quality studies characterizing country-specific prevalence, risk factors, physical and behavioral health complications, and optimal methods of assessment and counseling for youth vaping. Clinicians remain underexposed to this recent work, limiting translation of evidence into higher quality patient care. This review aims to provide pediatricians and other clinicians working with youth a clinically focused survey of key research findings and considerations based on recent evidence. This narrative review surveys emerging trends in EC use across different countries, reasons for youth vaping, characteristics of vaping materials that promote youth use, associations with combustible cigarette use, relation with cannabis and other illicit substances, physical and behavioral health risks associated with vaping, and methods of assessment, counseling, and intervention for problematic vaping in youth. Since vaping remains a relatively new phenomenon, long-term health consequences remain unknown.

Conclusion: Youth vaping is an increasingly well-studied phenomenon with both physical and behavioral health risks. Pediatricians and other youth-focused clinicians can apply the lessons of recent research in work with youth and their families.

\section{What is Known:}

- Youth vaping is an increasingly prevalent public health concern.

- Recent research demonstrates physical and behavioral health risks associated with vaping as well as methods for assessment, counseling, and intervention.

What is New:

- The current review summarizes the latest evidence in a clinically focused framework to facilitate translation of emerging knowledge to practice.
\end{abstract}

Keywords Adolescents $\cdot$ E-cigarettes $\cdot$ Vaping $\cdot$ Mental health $\cdot$ Review

\author{
Abbreviations \\ ADHD Attention-deficit/hyperactivity disorder \\ CC Combustible cigarette \\ EC Electronic cigarette
}

Communicated by Nicole Ritz.

Timothy D. Becker

Timothy.becker@mountsinai.org

Timothy R. Rice

timothy.rice@mountsinai.org

1 Department of Psychiatry, Icahn School of Medicine At Mount Sinai, One Gustave Levy Place, Box 1230, New York, NY 10019, USA
ENDS Electronic nicotine delivery systems

EVALI Electronic cigarette or vaping-associated acute lung injury

Screening, prevention, and treatment of substance use are core functions of adolescent healthcare [1]. Worldwide, youth electronic cigarette (EC) use, or vaping, has increased substantially over the past decade [2]. ECs are now often the first psychoactive substance used by youth in some settings [3], generating a surge in new research on health consequences of this trend. Adolescent use rates vary across Europe [4], and other countries [5] and clinician beliefs and practices regarding ECs vary considerably across settings [6-8]. 
To consolidate recent data concerning global epidemiology, physical and behavioral health risks, and clinical considerations, we review key facts and considerations for pediatricians based on recent studies, systematic reviews, and guidelines and recommendations. Adolescent vaping practices are ever-evolving, including during the COVID19 pandemic [9]. To provide best practices in their care, pediatricians must be familiar with the most recent evidence on this global public health concern.

\section{What is vaping and what distinguishes it from conventional cigarette use?}

Contemporary ECs were introduced in 2003 by a Chinese inventor and spread to Europe and North America in 2006, initially promoted as a smoking cessation aid in adults [10]. However, ECs have become particularly popular among nicotine-naïve youth, with use reaching epidemic proportions in some areas [11, 12]. EC use became particularly popular among North American adolescents, with rates often exceeding rates of combustible cigarette (CC) use [13]. In Canada, lifetime EC use rates reached 37\%, and current use rates reached $14.6 \%$ among adolescents in 2018 [13]. In the USA, current use rates reached a peak of $27.5 \%$ among high school students in 2019, before decreasing to $19.6 \%$ in 2020 (data collected from January through March, prior to the onset of COVID-19 restrictions in the USA) [14]. Among currently using US adolescents, $38.9 \%$ reported using at least 20 days per month, and $83 \%$ reported use of flavored ECs [14]. EC use has also been popular among UK adolescents, with lifetime use rates of $32.7 \%$ and current use rate of $8.9 \%$ in 2018, which in contrast to the USA were slightly lower than the CC use rate among UK youth [13]. Limited comparable data exist to make reliable cross-national comparisons of use rates between European countries, although rates generally appear lower than in North America [4]. In a 2016-2017 study among adolescents in seven Western European cities, 35.5\% endorsed lifetime EC use (ranging from $23 \%$ in Germany to nearly $50 \%$ in Italy and Belgium), with $6.6 \%$ reporting EC current use (i.e., monthly or more frequently), compared to $17.2 \%$ current CC use [4]. Among university students across several Central and Eastern European countries in 2017-2018, while $43.7 \%$ reported lifetime use of EC, only $2.9 \%$ were current EC users, well below rates of current CC use (12.3\%) [15]. South Korean adolescents' current use rates (3\% and 1\% among young men and women, respectively) are also comparatively lower and have remained stable from 2016 to 2018 [16]. Restrictiveness of policies around mass marketing and sale to minors has been identified as a factor contributing to differences in EC uptake across locales $[5,17]$.
ECs are battery-powered devices that contain a liquid that becomes aerosolized when heated, providing nicotine to users with less irritation than CCs [18]. ECs are also known as E-cigs and vape pens and are a type of electronic nicotine delivery systems (ENDS). E-liquids may contain a combination of propylene glycol or glycerin bases, flavoring compounds, nicotine, and/or other psychoactive substances such as cannabis derivates. EC design has evolved from single-use devices that resembled CCs, to rechargeable and refillable "vape pens," to increasingly personalizable modular products ("pod mods") [19]. Pod mod devices, initially marketed by JUUL Labs, Inc. and now sold by numerous vaping brands, have become particularly popular among youth. These devices were designed and marketed for their ability to deliver nicotine faster than competing ENDS [13] and can deliver particularly high levels of nicotine [18, 20]. While nicotine concentration in traditional CCs is approximately $1.5-2 \%(1.5-2 \mathrm{mg} / \mathrm{ml})$ ([21], as cited in [18]), the concentration of nicotine in some pod-based devices is as high as 5\%, and daily use of one-quarter of a pod meets the addictive threshold of nicotine [18]. The increased use of high-dose nicotine products has raised alarm among health experts that a new generation may become addicted to nicotine [12].

\section{Why do youth vape?}

Youth uptake of ECs has occurred in the context of youthtargeted marketing, social media promotion of ECs, and peer influences. A study of US high school seniors identified three main motivations to vape: taste and entertainment (63\%), experimentation (29\%), and to replace CCs (7\%) [22]. In comparison, a German study found that the vast majority of German youth (aged 14-19) cited curiosity (73.1\%) as their reason for EC use, followed by quitting tobacco use (14.9\%) and as a complement to tobacco use (7.5\%) [23]. In a systematic review of six studies among young adults in varied settings (i.e., USA, Romania, France, New Zealand, and Saudi Arabia), curiosity and EC use by friends were the primary reasons for EC initiation among non-smokers [24]. Among former and current CC users, ECs were used due to perceptions of harm reduction, to aid smoking cessation, to use in smoking-restricted areas, for lower cost compared to CCs, or for flavoring [24]. Studies in Europe and Taiwan have identified male gender, older age, and parental and peer smoking as risk factors for EC use and dual use of ECs and CCs $[4,25,26]$.

Some countries have been slow to regulate EC marketing [27], leaving youth vulnerable to advertisers. Advertising has consistently been associated with youths' intention to use ECs [28]. A systematic review found that in addition to traditional marketing, often utilizing youth-directed 
strategies, social media platforms have been widely used for public discussion of ECs in a manner that produces largely positive or neutral EC portrayals [29].

Although policy environments seem to account for some cross-country variation in EC use [5, 17], legal restrictions alone do not fully explain variation across countries. For example, Germany has one of the least restrictive nicotine product environments according to the Tobacco Control Scale [30]. Yet, Germany has lower youth EC use rates than Finland and Ireland, two of the most restrictive European countries [30]. These findings demonstrate the need to further study other factors accounting for cross-country variation [4].

Youth EC use is also influenced by the attitudes and behaviors of others around them toward CC use. In Europe, EC use rates have correlated with city-level CC use rates [4]. Peer influence is important [31]. Parent CC use is a risk factor for youth EC use, and parents' attitudes around EC use influence adolescent use [32]. Certain family systems may have difficulty setting appropriate limits on adolescent access to and use of ECs: In one study, adolescents with divorced parents were $51 \%$ more likely to use ECs than those with married parents [33].

\section{Candy or drugs? What youth vape and how they get it}

Although ECs are most associated with nicotine, they are a vehicle for substance use that may or may not contain nicotine. In a 2017 nationally representative survey among US adolescents, $25 \%$ of current EC users reported vaping only flavoring, while the rest reported vaping nicotine (45\%), marijuana (13\%), or both (17\%) [34]. Among European adolescents who had ever used ECs, $43 \%$ reported vaping non-nicotine liquids, $37 \%$ nicotine, and $19.6 \%$ reported not knowing what they vaped [4].

Many youth may misperceive or do not know what they are vaping. US adolescents commonly misunderstand that nicotine is a tobacco derivative, and those who report vaping only flavoring have been found to have particularly limited knowledge about nicotine use [35]. In one study, $40 \%$ of youth reporting use of nicotine-free products had urinary evidence of nicotine [36].

Flavors both attract youth to EC use and perpetuate ongoing use. US adolescents reported more interest in trying ECs offered by a friend if flavored like fruit, candy, or menthol than tobacco [37]. US and UK adolescents have expressed the belief that fruity flavored ECs are less harmful than tobacco-flavored ECs [37, 38]. Adolescents whose first EC is flavored progress to current and more frequent use faster than peers whose initial exposure was unflavored [39], and use of
ECs with nontraditional flavors (e.g., candy, fruit) by adolescents was associated with vaping continuation and puffs per use 6 months later compared to traditional flavors (e.g., menthol, tobacco, and flavorless) [40].

Although many locales restrict the sale of ECs to adolescents [27], underage youth find ways of obtaining devices. Most US adolescents who vape own their own device, although they also frequently share devices with peers [41]. One study found that most US youth obtained ECs through online or brick-and-mortar store purchases, while informal purchases, having others purchase for them, or receipt as gifts were less common [41]. In another study, e-liquids were most often obtained by US adolescents through social sources [42]. In a recent study undertaken during the COVID-19 pandemic following heightened regulations in the US surrounding EC marketing, a majority of US youth reported reduction in EC use due to difficulties obtaining EC products. However, youth who continued using ECs shifted toward buying products online, including by receiving deliveries without undergoing age verification [43].

\section{Does vaping lead to, or help prevent, combustible cigarette use?}

Many studies have investigated the concern that youth EC use may increase risk for initiation of CCs, threatening to undo decades of progress in reducing population level young adult tobacco use [44]. ECs are being used by youth with a lower risk profile than recent youth CC users: one analysis of nationally representative US data found that only $11-23 \%$ of EC-only users would have been predicted by risk factors to be $\mathrm{CC}$ users [45].

Additionally, ECs may be an independent risk factor for CC use, suggesting a "gateway effect," although this remains subject to debate. A meta-analysis of 9 longitudinal studies $(n=17,389)$ of CC-naïve youth found that EC use was significantly associated with subsequent $\mathrm{CC}$ use, even when controlling for known demographic and behavioral risk factors for CC use [46]. A subsequent meta-analysis of 11 studies, though finding the same effect, raised concern that existing evidence remains limited by attrition, publication bias, and inadequate adjustment for confounders [47]. However, studies extensively controlling for smoking risk factors still find ECs independently associated with later CC use [48]. A small longitudinal study found that nicotine doses in ECs were associated with frequency and intensity of subsequent $\mathrm{EC}$ and $\mathrm{CC}$ use [49]. Among youth who had already experimented with CCs, use of ECs positively associated with progression to current established smoking, suggesting that in youth already 
starting to use CCs, ECs may contribute to rather than reduce the risk of progression to regular CC use [50].

\section{How does vaping relate to use of marijuana and other substances?}

Nicotine affects the neural pathways underlying pleasure and reward and may increase the brain's long-term sensitivity to other psychoactive substances and drug-seeking behaviors throughout adulthood [51, 52]. In the USA, the surge in EC popularity happened concurrently with a loosening of cannabis regulations, and studies have found that many youth use both ECs and cannabis [3]. A recent US study using cross-sectional data from 2000 to 2019 suggests that adolescents who use cannabis have declining rates of CC use and increasing rates of EC use [53]. In a meta-analysis, the odds of current or past cannabis use were significantly higher among youth who had used ECs, with particularly strong associations among adolescents [3], whose brains are viewed as more vulnerable to addiction than older youth [54]. Three longitudinal studies suggested a temporal relationship in which EC use predates cannabis use [55-57], suggesting that addressing EC use is an important means of preventing youth cannabis use and of mitigating the adverse neuropsychological effects of cannabis [58, 59]. Additionally, another meta-analysis found EC use associated with a six-fold risk of alcohol use and binge drinking in adolescents, though most included studies were cross-sectional and did not sufficiently adjust for confounders [60].

\section{What are the physical health risks of vaping?}

Although EC aerosols appear less cytotoxic than compounds inhaled during CC use [106], they pose their own physical health risks, especially on the respiratory system [61]. ECs may potentially expose users to heavy metals from batteries and heating coils that may be carcinogenic or toxic to the heart and lungs, though the long-term effects of these exposures among vapers remain unclear [62]. E-liquid bases (e.g., propylene glycol) can be respiratory irritants [63, 64] (see Table 1).

During the summer of 2019, North America underwent an outbreak of EC- or vaping-associated acute lung injury (EVALI). Dozens of deaths and thousands of cases of acute respiratory compromise due to nonspecific acute injury occurred [11]. EVALI was most closely associated with vaping cannabis derivates with vitamin $\mathrm{E}$ acetate, which was found present in a large majority of bronchoalveolar lavage samples in one case series of patients with EVALI [65]; however other pathogenic components have also likely contributed [66]. Radiographic findings in adolescents with EVALI include centrilobular ground-glass nodules and ground-glass opacities with subpleural sparing [67].

Additional vaping-related health risks have also been described. Vaping and ingesting e-liquids have been associated with seizures [68]. ECs adversely impact oral health, though possibly less severely than CC [69]. Like CCs, secondhand EC vapor exposure may also pose a health risk and contaminate indoor air quality, although also seemingly less so than secondhand CC smoke [70].

Table 1 Major toxic constituents in e-cigarettes

1. Nicotine

- Reaches brain within $15 \mathrm{~s}$ after puff on a CC, likely similar with EC use-creates immediate pleasurable effects that reinforce use

- Not alone thought to be a human carcinogen

- Activates the sympathetic nervous system - thought to be associated with risk of myocardial ischemia, arrythmias, cardiac tissue remodeling, thrombogenesis, and endothelial dysfunction

- Comparison to CCs: Degree of exposure to nicotine varies considerably depending on device characteristics, e-liquids, and how ECs are used

2. Humectants-EC liquids usually contain propylene glycol and glycerol as solvent carriers to generate aerosols

- When overheated both humectants decompose into toxic carbonyl compounds

- Additionally, inhaled propylene glycol at concentrations in ECs can cause eye and throat irritation

3. Flavorings-dozens of flavoring compounds have been used in ECs (e.g., menthol, benzaldehyde, vanillin, diacetyl)

- These compounds are generally considered safe as food additives.

The effects of inhaled flavoring compounds on the pulmonary system are less clear

- Flavorings have been found to form aldehydes and other respiratory irritants when heated
4. Carbonyl compounds-e.g., formaldehyde, acetaldehyde, acrolein - Generated by the heating of humectants and flavorings in e-liquids, particularly in devices with battery power greater than $3 \mathrm{~V}$ - Known to be carcinogenic and respiratory irritants

- Comparison to CCs: Under typical use, exposure to toxic carbonyls in ECs appears significantly less than with CC use.

5. Metals-lead, nickel, chromium, manganese, aluminum, tin, and iron have been found in EC emissions

- Originate from the heating coil or other device parts, such as wires, joints, or batteries

- Metal levels vary considerably across products and studies and are theoretically toxic to multiple organ systems.

- Comparison to CCs: Limited evidence suggests that metal exposure is greater in ECs than CCs, except for cadmium which is markedly higher in CCs.

National Academies of Sciences, Engineering, and Medicine. Public health consequences of e-cigarettes. The National Academies 
During the COVID-19 pandemic, adolescents may violate social distancing and risk viral exposure as mediated through neurobiologically determined [71] valuation of risks [51]: sharing of vaping devices and mask-free use increases the risk of transmission, increasing the risk of morbidity for the family upon return to home.

\section{How does vaping relate to mental health?}

Adults with mental illness suffer disproportionately from tobacco-related morbidity and mortality, and most begin smoking before age 21 , making tobacco prevention in young people with mental illness an important priority $[73,74]$. Youth with mental illness may be attracted to ECs due to beliefs that ECs may help to modify their psychiatric symptoms, in attempts to offset side effects of psychotropic medications, or due to common underlying risk factors for mental illness and substance use (e.g., executive function deficits) [75, 76]. In a recent systematic review of vaping and mental health comorbidities in youth, vaping has been consistently associated with depression, suicidality, attention-deficit/hyperactivity disorder (ADHD), and conduct disorder in adolescents [75]. Nicotine exposure adversely affects brain development in animal models and increases risk of further substance use [77-79] and broader mental illness [80-82], as well as problems with learning and memory [83]. Due to a lack of longitudinal studies examining mental health among EC users, it remains unclear to what extent vaping effects the longterm trajectory of psychopathology [75]. Among extant small longitudinal studies in youth, one study suggested a bidirectional relationship between EC use and depressive symptoms [84], while another found that ADHD symptoms predicted onset of EC use but not worsening of ADHD symptoms [85].

\section{Assessment of vaping in youth}

Clinicians can most effectively manage the potential risks of EC use on physical health, mental health, and substance use by routinely assessing patients for EC use. Screening tools for youth EC use have not yet been developed and validated, but questions about EC use can be easily integrated into existing assessment methods [86]. The absence of electronic medical record prompts for the assessment of EC use has been identified as an area requiring attention in adolescent primary care visits [87]. Table 2 offers items to consider for assessment based on available evidence $[1,19,86]$.

\section{Counseling youth and families about vaping}

outh often have misconceptions about vaping, and parents may mistake the possible benefits of ECs among adult smokers [72, 89] for harmlessness in youth. ECs have not been established as an effective intervention for nicotine cessation in youth [89]. Clinicians can provide information about the risks of vaping, while acknowledging that some long-term risks remain unclear. Possible points to discuss with families are listed in Table 3.

\section{Interventions for problematic vaping}

Many youth want to quit vaping [88]. At the individual patient level, clinical interventions specific to vaping remain underdeveloped. To date, general principles and established treatments for CC use have been applied. This approach carries potential limitations: a qualitative study of Canadian youth and young adults identified several differences between vaping and $\mathrm{CC}$ use that may influence the cessation process [90]. In this study, unlike CC users, EC users reported their enjoyment of flavors as a reason for ongoing use. The convenience and discreetness of vaping (e.g., lack of distinct smell) contribute to ease of EC use throughout the day and in many locations, leading to a lack of awareness of how much they are vaping. Lastly, youth in this study also cited a lack of trusted information about health risks of vaping compared to CCs and greater perceived social acceptability of vaping compared to CC as factors complicating EC cessation.

Like all substance use disorders, clinicians can begin by engaging youth in strength-based motivational interviewing, weighing the risks of vaping against perceived benefits, and identifying specific goals for use reduction or cessation with youth who wish to quit [86]. Youth often cite health, cost, freedom from addiction, social considerations, and academic performance as reasons for wishing to quit vaping $[88,90]$. These goals may include eliminating use of favored flavors that although not addictive seem to reinforce use in youth. Social media information and misinformation about EC has caused confusion for some youth that may reduce motivation for cessation [90]; medical professionals can provide credible information about health risks to reinforce motivation for change. Since youth EC users may be less aware of how much they are using (e.g., how many pods per week) than CC users, helping the youth keep a log of use may provide a useful means of developing insight into their use [90]. Clinicians should encourage youth to allow family involvement (e.g., by restricting access to vaping devices, supporting 
Table 2 Questions for assessing EC use

Question
Have you ever used an e-cig, vape pen, or mod pod (e.g., JUUL,
MYLE, NJoy)?
What type of device do you use?

What substance have you vaped?

Have you had any problems at school, with parents, or the police because of vaping?

Where do you obtain ECs and EC products, such as e-liquids? What age did you start vaping?

How often do you vape (days/week, times/day, puffs/use)?

How often do you have to replace cartridges or refill the device?

Screen for symptoms of dependence: have you had cravings, difficulty cutting back use, or developed withdrawal symptoms when you were not able to vape?

Do you use other substances?

Do your friends or relatives vape, including parents in the home?

What risks do you take to vape?
Considerations

Higher battery output voltages increase risk of chemical reactions that create toxic products $[95,96]$. Devices with user-adjustable voltages may lead to adolescents using higher voltages (to attain greater vapor intensities) and therefore inhaling more toxic products

Flavoring: Flavoring increases the risk of both ongoing use and higher amounts of usage [40] as well as misperceptions of harmlessness [37]

Nicotine: Higher nicotine concentration has been associated with increased intensity of daily EC use and greater CC and EC use six months later [49]

Cannabis derivatives and other substances: Non-nicotine substances can increase the risk of alternate substance dependencies, EVALI, and other problems [66, 97]

Adolescent vaping is associated with delinquency [98], while use in school can provoke consequences including suspension or expulsion, even while school administrators and teachers may have limited awareness of policies [99]

Vaping may heighten family conflict around EC use

Legal consequences can derive from use in prohibited locations or underage purchase/distribution of vaping products

Social consequences can result from media posts surrounding vaping [100, 101]. In one study, 1 in 25 social media posts referenced use during school hours [100]

Access from the black market may be more hazardous [102]

Younger age of onset poses greater vulnerability to addiction [51, 54]

Use may range from infrequent use that requires counseling and monitoring to dependence that necessitates treatment

Dependence indicates need for closer follow-up and consideration of pharmacologic interventions [86]

Vaping is a risk factor for other substance use [56, 57]

Peer vaping is a common entry point and perpetuating factor for adolescent vaping [41] that may complicate quit efforts

Parental modeling is important, and as vaping becomes more prevalent among parents with inconsistent smoke-free and vape-free structures in the home and car [88], assessment of family use patterns is indicated

Questioning of practices during the COVID-19 pandemic may be particularly important for protecting adolescent and family health [9] adherence to behavioral goals, and positively reinforcing change) [86]. Parents who smoke should also be referred to smoking cessation resources. When available, individual or group cognitive behavioral therapy for nicotine use can help youth manage symptoms and prevent relapse with good efficacy on quit rates [91]. Mobile apps, such as the "quitSTART" app, can help teens track cessation goals and manage symptoms [107], and text messaging-based programs such as "This is Quitting" have shown effectiveness for facilitating abstinence in a recent randomized trial [92, 93].

Nicotine replacement therapies and bupropion have been found safe and effective in adults, but evidence of effectiveness in adolescents is more limited, and effectiveness seems enhanced when combined with psychosocial interventions [91]. Despite limited evidence for pharmacotherapy, given the relative safety of the medications and the potential harms of nicotine dependence, combination long-acting patch and short-acting as needed gum or lozenges have been recommended for youth under 18 looking to quit vaping [86].

On the population level, school-based interventions, media campaigns, and policy proposals have been proposed to help mitigate EC use [94, 95]. Peer-led network-informed intervention programs show promise [31]. Clinicians can advocate for policies that restrict where vaping products are 
Table 3 Counseling Youth and Families about ECs

- E-liquids often contain nicotine even if they have fruity flavors.

Youth sometimes do not realize that their ECs contain nicotine [35, 36]

- Nicotine in ECs is the same predominant addictive compound found in tobacco products and can quickly lead to dependence, especially in youth. Nicotine dependence places you at risk of withdrawal symptoms such as irritability, difficulty concentrating, and depressed $\operatorname{mood}[91]$

- Although vaping is considered safer than CC in some ways, it has its own risks. Some ECs lead to very high doses of nicotine used, creating stronger addiction risk

- Youth who vape are at risk of acute health problems such as EVALI [66], seizures [68]. bad oral health [69], or injury from exploding devices [103, 104]

- Vaping appears to increase the risk of becoming a CC smoker [44, 46] and may also increase the risk of other substance use problems $[3,60]$
- EC aerosols contain heavy metals, fine particles, and other substances that may be toxic or cancer-causing to vapers and bystanders [70], so vaping indoors should be avoided

- Nicotine and cannabis both affect neurodevelopment and may lead to problems with sleep, concentration, memory, and mental health [75]. Earlier substance use likely increases these risks [51, 54]

- Peer influence is important [31], and adolescents' perceptions of the importance of peer influence predicts EC use [105]. Counseling teens and their families on the benefits of distancing from negative peer groups may reduce risk of initiating or sustaining vaping

- Vaping may increase your child's risk of getting and spreading COVID-19 [9] sold (e.g., banning sales near schools), restrict sales to youth, restrict vaping indoors or in public places, ban advertising, require warning labels on packaging, and ban flavors that are attractive to youth [94, 95].

\section{Conclusion}

Youth vaping is now a well-studied phenomenon with various physical and behavioral health risks, some of which differ from traditional smoking. Although vaping-specific treatments remain underdeveloped, pediatricians and other youth clinicians can apply the lessons of recent research to counsel youth and their families and prevent long-term complications of vaping-related nicotine addiction.

Authors' Contributions TDB: Developed idea and strategy and wrote first draft of paper. TRR: Participated in the development of the idea and design, co-wrote and revised the article, checked all the processes of the article.

\section{Declarations}

Ethics approval This article does not contain any studies with human participants or animals performed by any of the authors.

Conflict of interest The authors declare no competing interests.

\section{References}

1. Michaud P-A, Bélanger R, Mazur A et al (2020) How can primary care practitioners address substance use by adolescents? A position paper of the EUROPEAN academy of PAEDIATRICS. Eur J Pediatr 179:1297-1305. https://doi.org/10.1007/ s00431-020-03596-6
2. Gentzke AS, Creamer M, Cullen KA, et al (2019) Vital Signs: tobacco product use among middle and high school students United States, 2011-2018. MMWR Morb Mortal Wkly Rep 68:157-164. https://doi.org/10.15585/mmwr.mm6806e1

3. Chadi N, Schroeder R, Jensen JW, Levy S (2019) Association between electronic cigarette use and marijuana use among adolescents and young adults: a systematic review and metaanalysis. JAMA Pediatr 173:e192574. https://doi.org/10.1001/ jamapediatrics.2019.2574

4. Kinnunen JM, Rimpelä AH, Lindfors PL et al (2021) Electronic cigarette use among 14- to 17-year-olds in Europe. Eur J Public Health 31:402-408. https://doi.org/10.1093/eurpub/ckaa145

5. Cho H-J, Dutra LM, Glantz SA (2018) Differences in adolescent e-cigarette and cigarette prevalence in two policy environments: South Korea and the United States. Nicotine Tob Res 20:949953. https://doi.org/10.1093/ntr/ntx198

6. Koprivnikar H, Zupanič T, Farkas J (2020) Beliefs and practices regarding electronic cigarettes in smoking cessation among healthcare professionals in Slovenia. Tob Prev Cessat 6:3. https:// doi.org/10.18332/tpc/115029

7. Ferrara P, Shantikumar S, Cabral Veríssimo V et al (2019) Knowledge about e-cigarettes and tobacco harm reduction among public health residents in Europe. Int J Environ Res Public Health 16:2071. https://doi.org/10.3390/ijerph16122071

8. Erku DA, Gartner CE, Morphett K, Steadman KJ (2020) Beliefs and self-reported practices of health care professionals regarding electronic nicotine delivery systems: a mixed-methods systematic review and synthesis. Nicotine Tob Res 22:619-629

9. Dumas TM, Ellis W, Litt DM (2020) What does adolescent substance use look like during the COVID-19 pandemic? Examining changes in frequency, social contexts, and pandemic-related predictors. J Adolesc Heal 67:354-361. https://doi.org/10.1016/j. jadohealth.2020.06.018

10. CASAA (2012) E-cigarette history: a historical timeline of electronic cigarettes. In: Consum. Advocates Smokefree Altern. Assoc. https://casaa.org/education/vaping/historical-timelineof-electronic-cigarettes/. Accessed 28 Feb 2021

11. King BA, Jones CM, Baldwin GT, Briss PA (2020) The EVALI and youth vaping epidemics - implications for Public Health. N Engl J Med 382:689-691. https://doi.org/10.1056/nejmp1916171

12. Besaratinia A, Tommasi S (2020) Vaping epidemic: challenges and opportunities. Cancer Causes Control 31:663-667. https:// doi.org/10.1007/s10552-020-01307-y 
13. Hammond D, Reid JL, Rynard VL, et al (2019) Prevalence of vaping and smoking among adolescents in Canada, England, and the United States: repeat national cross sectional surveys. BMJ 365:12219. https://doi.org/10.1136/bmj.12219

14. Wang TW, Neff LJ, Park-Lee E, et al (2020) E-cigarette use among middle and high school students - United States, 2020. MMWR Morb Mortal Wkly Rep 69:1310-1312. https://doi.org/ 10.15585/mmwr.mm6937e1

15. Brożek GM, Jankowski M, Lawson KA, et al 2019 The prevalence of cigarette and e-cigarette smoking among students in central and eastern Europe-results of the YUPESS study. Int J Environ Res Public Health 16:2297. https://doi.org/10.3390/ijerph16132297

16. Lee ES, Paek YJ (2020) Prevalence and correlates of the dual use of conventional and electronic cigarettes among Korean adolescents: 2016-2018 Korean youth risk behavior survey. J Korean Soc Res Nicotine Tob 11:64-74. https://doi.org/10. 25055/JKSRNT.2020.11.2.64

17. Hammond D, Reid JL, Burkhalter R, Rynard VL (2020) E-cigarette marketing regulations and youth vaping: cross-sectional surveys, 2017-2019. Pediatrics 146:e20194020. https://doi.org/10.1542/ peds.2019-4020

18. Jackler RK, Ramamurthi D (2019) Nicotine arms race: JUUL and the high-nicotine product market. Tob Control 28:623-628. https://doi.org/10.1136/tobaccocontrol-2018-054796

19. Ker S, Peckham E, Gilbody S, Bonner S (2019) Everything you wanted to know about e-cigarettes and vaping but were afraid to ask: a guide for mental health clinicians. BJPsych Adv 25:279286. https://doi.org/10.1192/bja.2019.36

20. Goniewicz ML, Boykan R, Messina CR et al (2019) High exposure to nicotine among adolescents who use Juul and other vape pod systems ('pods'). Tob Control 28:676-677. https://doi.org/ 10.1136/tobaccocontrol-2018-054565

21. Benowitz NL, Henningfield JE (1994) Establishing a nicotine threshold for addiction - the implications for tobacco regulation. N Engl J Med 331:123-125. https://doi.org/10.1056/ NEJM199407143310212

22. Evans-Polce RJ, Patrick ME, Lanza ST et al (2018) Reasons for vaping among U.S. 12th Graders. J Adolesc Health 62:457-462. https://doi.org/10.1016/j.jadohealth.2017.10.009

23. Eichler M, Blettner M, Singer S (2016) The use of e-cigarettes. Dtsch Aerzteblatt Online. 113:847-854. https://doi.org/10.3238/ arztebl.2016.0847

24. Kinouani S, Leflot C, Vanderkam P et al (2020) Motivations for using electronic cigarettes in young adults: a systematic review. Subst Abus 41:315-322

25. Hanewinkel R, Isensee B (2015) Risk factors for e-cigarette, conventional cigarette, and dual use in German adolescents: a cohort study. Prev Med (Baltim) 74:59-62. https://doi.org/10. 1016/j.ypmed.2015.03.006

26. Chen P-C, Chang L-C, Hsu C, Lee Y-C (2019) Dual use of e-cigarettes and traditional cigarettes among adolescents in Taiwan, 2014-2016. Nicotine Tob Res 21:48-54. https://doi.org/10. 1093/ntr/nty003

27. Kennedy RD, Awopegba A, De León E, Cohen JE (2017) Global approaches to regulating electronic cigarettes. Tob Control 26:440-445. https://doi.org/10.1136/tobaccocontrol-2016-053179

28. Amin S, Dunn AG, Laranjo L (2020) Social influence in the uptake and use of electronic Cigarettes: a systematic review. Am J Prev Med 58:129-141. https://doi.org/10.1016/j.amepre.2019. 08.023

29. Collins L, Glasser AM, Abudayyeh H et al (2019) E-cigarette marketing and communication: how e-cigarette companies market e-cigarettes and the public engages with e-cigarette information. Nicotine Tob Res 21:14-24
30. Joossens L, Feliu A, Fernandez E. The Tobacco Control Scale 2019 in Europe. Brussels: Association of European Cancer Leagues, Catalan Institute of Oncology; 2020. Available from: http://www.tobaccocontrolscale.org/TCS2019.pdf

31. Wyman PA, Rulison K, Pisani AR et al (2021) Above the influence of vaping: Peer leader influence and diffusion of a networkinformed preventive intervention. Addict Behav 113:106693. https://doi.org/10.1016/j.addbeh.2020.106693

32. Trucco EM, Cristello JV, Sutherland MT (2021) Do parents still matter? The impact of parents and peers on adolescent electronic cigarette use. J Adolesc Heal 68:780-786. https://doi.org/10. 1016/j.jadohealth.2020.12.002

33. Watkins NK, Ohannessian CMC (2020) Timing of vape use among adolescents: differences by family structure. Drug Alcohol Depend 209:107953. https://doi.org/10.1016/j.drugalcdep.2020.107953

34. Dai H, Siahpush M (2020) Use of e-cigarettes for nicotine, marijuana, and just flavoring among U.S. Youth Am J Prev Med 58:244-249. https://doi.org/10.1016/j.amepre.2019.09.006

35. Pepper JK, Farrelly MC, Watson KA (2018) Adolescents' understanding and use of nicotine in e-cigarettes. Addict Behav 82:109-113. https://doi.org/10.1016/j.addbeh.2018.02.015

36. Boykan R, Messina CR, Chateau G et al (2019) Self-reported use of tobacco, E-cigarettes, and marijuana versus urinary biomarkers. Pediatrics 143:e20183531. https://doi.org/10.1542/peds. 2018-3531

37. Pepper JK, Ribisl KM, Brewer NT (2016) Adolescents' interest in trying flavoured e-cigarettes. Tob Control 25:ii62-ii66. https:// doi.org/10.1136/tobaccocontrol-2016-053174

38. Ford A, MacKintosh AM, Bauld L et al (2016) Adolescents' responses to the promotion and flavouring of e-cigarettes. Int J Public Health 61:215-224. https://doi.org/10.1007/ s00038-015-0769-5

39. Audrain-McGovern J, Rodriguez D, Pianin S, Alexander E (2019) Initial e-cigarette flavoring and nicotine exposure and e-cigarette uptake among adolescents. Drug Alcohol Depend 202:149-155. https://doi.org/10.1016/j.drugalcdep.2019.04.037

40. Leventhal AM, Goldenson NI, Cho J et al (2019) Flavored e-cigarette use and progression of vaping in adolescents. Pediatrics 144:e20190789. https://doi.org/10.1542/peds.2019-0789

41. Pepper JK, Coats EM, Nonnemaker JM, Loomis BR (2019) How do adolescents get their e-cigarettes and other electronic vaping devices? Am J Heal Promot 33:420-429. https://doi.org/10.1177/ 0890117118790366

42. McKeganey N, Russell C, Katsampouris E, Haseen F (2019) Sources of youth access to JUUL vaping products in the United States. Addict Behav Reports 10:100232. https://doi.org/10. 1016/j.abrep.2019.100232

43. Gaiha SM, Lempert LK, Halpern-Felsher B (2020) Underage youth and young adult e-cigarette use and access before and during the coronavirus disease 2019 pandemic. JAMA Netw Open 3:e2027572. https://doi.org/10.1001/jamanetworkopen.2020.27572

44. Pierce JP, Chen R, Leas EC et al (2021) Use of e-cigarettes and other tobacco products and progression to daily cigarette smoking. Pediatrics 147:e2020025122. https://doi.org/10.1542/peds. 2020-025122

45. Dutra LM, Glantz SA (2017) E-cigarettes and national adolescent cigarette use: 2004-2014. Pediatrics 139:e20162450. https://doi. org/10.1542/peds.2016-2450

46. Soneji S, Barrington-Trimis JL, Wills TA et al (2017) Association between initial use of e-cigarettes and subsequent cigarette smoking among adolescents and young adults. JAMA Pediatr 171:788. https://doi.org/10.1001/jamapediatrics.2017.1488

47. Chan GCK, Stjepanović D, Lim C, et al (2020) Gateway or common liability? A systematic review and meta-analysis of studies 
of adolescent e-cigarette use and future smoking initiation. Addiction 116:743-756. https://doi.org/10.1111/add.15246

48. Epstein M, Bailey JA, Kosterman R, et al (2020) E-cigarette use is associated with subsequent cigarette use among young adult non-smokers, over and above a range of antecedent risk factors: a propensity score analysis. Addiction add.15317. https://doi.org/ 10.1111/add.15317

49. Goldenson NI, Leventhal AM, Stone MD et al (2017) Associations of electronic cigarette nicotine concentration with subsequent cigarette smoking and vaping levels in adolescents. JAMA Pediatr 171:1192. https://doi.org/10.1001/jamapediatrics.2017. 3209

50. Chaffee BW, Watkins SL, Glantz SA (2018) Electronic cigarette use and progression from experimentation to established smoking. Pediatrics 141:e20173594. https://doi.org/10.1542/peds. 2017-3594

51. Casey BJ, Jones RM (2010) Neurobiology of the adolescent brain and behavior: Implications for substance use disorders. J Am Acad Child Adolesc Psychiatry 49:1189-1201

52. Ren M, Lotfipour S (2019) Nicotine gateway effects on adolescent substance use. West J Emerg Med 20:696-709. https://doi. org/10.5811/westjem.2019.7.41661

53. Terry-McElrath YM, O'Malley PM, Johnston LD (2020) Changes in the order of cigarette and marijuana initiation and associations with cigarette use, nicotine vaping, and marijuana use: U.S. 12th Grade Students, 2000-2019. Prev Sci 21:960-971. https://doi.org/10.1007/s11121-020-01150-2

54. Gray KM, Squeglia LM (2018) Research review: what have we learned about adolescent substance use? J Child Psychol Psychiatry Allied Discip 59:618-627

55. Unger JB, Soto DW, Leventhal A (2016) E-cigarette use and subsequent cigarette and marijuana use among Hispanic young adults. Drug Alcohol Depend 163:261-264. https://doi.org/10. 1016/j.drugalcdep.2016.04.027

56. Dai H, Catley D, Richter KP et al (2018) Electronic cigarettes and future marijuana use: a longitudinal study. Pediatrics 141:e20173787. https://doi.org/10.1542/peds.2017-3787

57. Audrain-Mcgovern J, Stone MD, Barrington-Trimis J et al (2018) Adolescent e-cigarette, hookah, and conventional cigarette use and subsequent marijuana use. Pediatrics 142:e20173616. https:// doi.org/10.1542/peds.2017-3616

58. Bagot KS, Milin R, Kaminer Y (2015) Adolescent initiation of cannabis use and early-onset psychosis. Subst Abus 36:524-533

59. Meier MH, Caspi A, Ambler A et al (2012) Persistent cannabis users show neuropsychological decline from childhood to midlife. Proc Natl Acad Sci U S A 109:E2657-E2664. https:// doi.org/10.1073/pnas.1206820109

60. Rothrock AN, Andris H, Swetland SB et al (2020) Association of e-cigarettes with adolescent alcohol use and binge drinkingdrunkenness: a systematic review and meta-analysis. Am J Drug Alcohol Abuse 46:684-698. https://doi.org/10.1080/00952990. 2020.1771723

61. Hamberger ES, Halpern-Felsher B (2020) Vaping in adolescents. Curr Opin Pediatr 32:378-383. https://doi.org/10.1097/MOP. 0000000000000896

62. Gaur S, Agnihotri R (2019) Health effects of trace metals in electronic cigarette aerosols-a systematic review. Biol Trace Elem Res 188:295-315

63. Ratajczak A, Feleszko W, Smith DM, Goniewicz M (2018) How close are we to definitively identifying the respiratory health effects of e-cigarettes? Expert Rev Respir Med 12:549-556. https://doi.org/10.1080/17476348.2018.1483724

64. Marini S, Buonanno G, Stabile L, Ficco G (2014) Short-term effects of electronic and tobacco cigarettes on exhaled nitric oxide. Toxicol Appl Pharmacol 278:9-15. https://doi.org/10. 1016/j.taap.2014.04.004
65. Blount BC, Karwowski MP, Shields PG et al (2020) Vitamin e acetate in bronchoalveolar-lavage fluid associated with EVALI. N Engl J Med 382:697-705. https://doi.org/10.1056/NEJMoa1916433

66. Jonas AM, Raj R (2020) Vaping-related acute parenchymal lung injury: a systematic review. Chest 158:1555-1565

67. Thakrar PD, Boyd KP, Swanson CP et al (2020) E-cigarette, or vaping, product use-associated lung injury in adolescents: a review of imaging features. Pediatr Radiol 50:338-344. https:// doi.org/10.1007/s00247-019-04572-5

68. Faulcon LM, Rudy S, Limpert J et al (2020) Adverse experience reports of seizures in youth and young adult electronic nicotine delivery systems users. J Adolesc Heal 66:15-17. https://doi.org/ 10.1016/j.jadohealth.2019.10.002

69. Yang I, Sandeep S, Rodriguez J (2020) The oral health impact of electronic cigarette use: a systematic review. Crit Rev Toxicol 50:97-127. https://doi.org/10.1080/10408444.2020.1713726

70. Hess IMR, Lachireddy K, Capon A (2016) A systematic review of the health risks from passive exposure to electronic cigarette vapour. Public Heal Res Pract 26:e2621617. https://doi.org/10. 17061/phrp2621617

71. Casey BJ, Jones RM, Somerville LH (2011) Braking and accelerating of the adolescent brain. J Res Adolesc 21:21-33. https:// doi.org/10.1111/j.1532-7795.2010.00712.x

72. Hajek P, Phillips-Waller A, Przulj D et al (2019) A randomized trial of e-cigarettes versus nicotine-replacement therapy. N Engl J Med 380:629-637. https://doi.org/10.1056/nejmoa1808779

73. Williams JM, Steinberg ML, Griffiths KG, Cooperman N (2013) Smokers with behavioral health comorbidity should be designated a tobacco use disparity group. Am J Public Health 103:1549-1555. https://doi.org/10.2105/AJPH.2013.301232

74. Prochaska JJ, Das S, Young-Wolff KC (2017) Smoking, mental illness, and public health. Annu Rev Public Health 38:165-185. https://doi.org/10.1146/annurev-publhealth-031816-044618

75. Becker TD, Arnold MK, Ro V et al (2020) Systematic review of electronic cigarette use (vaping) and mental health comorbidity among adolescents and young adults. Nicotine Tob Res 23:415-425. https://doi.org/10.1093/ntr/ntaa171

76. Pentz MA, Shin H, Riggs N et al (2015) Parent, peer, and executive function relationships to early adolescent e-cigarette use: a substance use pathway? Addict Behav 42:73-78. https://doi.org/ 10.1016/j.addbeh.2014.10.040

77. Lai S, Lai H, Page JB, McCoy CB (2000) The association between cigarette smoking and drug abuse in the United States. J Addict Dis 19:11-24. https://doi.org/10.1300/J069v19n04_ 02

78. Kandel D, Kandel E (2015) The gateway hypothesis of substance abuse: developmental, biological and societal perspectives. Acta Paediatr 104:130-137. https://doi.org/10.1111/apa.12851

79. Degenhardt L, Dierker L, Chiu WT et al (2010) Evaluating the drug use "gateway" theory using cross-national data: consistency and associations of the order of initiation of drug use among participants in the WHO World Mental Health Surveys. Drug Alcohol Depend 108:84-97. https://doi.org/10.1016/j. drugalcdep.2009.12.001

80. Yuan M, Cross SJ, Loughlin SE, Leslie FM (2015) Nicotine and the adolescent brain. J Physiol 593:3397-3412. https://doi.org/ 10.1113/JP270492

81. Goriounova NA, Mansvelder HD (2012) Short- and long-term consequences of nicotine exposure during adolescence for prefrontal cortex neuronal network function. Cold Spring Harb Perspect Med 2:a012120-a012120. https://doi.org/10.1101/ cshperspect.a012120

82. Smith RF, McDonald CG, Bergstrom HC et al (2015) Adolescent nicotine induces persisting changes in development of neural connectivity. Neurosci Biobehav Rev 55:432-443. https://doi. org/10.1016/j.neubiorev.2015.05.019 
83. Slotkin TA (2002) Nicotine and the adolescent brain: insights from an animal model. Neurotoxicol Teratol 24:369-384. https:// doi.org/10.1016/S0892-0362(02)00199-X

84. Lechner WV, Janssen T, Kahler CW et al (2017) Bi-directional associations of electronic and combustible cigarette use onset patterns with depressive symptoms in adolescents. Prev Med (Baltim) 96:73-78. https://doi.org/10.1016/j.ypmed.2016.12.034

85. Dvorsky MR, Langberg JM (2019) Cigarette and e-cigarette use and social perceptions over the transition to college: The Role of ADHD Symptoms. Psychol Addict Behav 33:318-330. https:// doi.org/10.1037/adb0000450

86. Hadland SE, Chadi N (2020) Through the haze: what clinicians can do to address youth VAPING. J Adolesc Heal 66:10-14. https://doi.org/10.1016/j.jadohealth.2019.10.009

87. LeLaurin JH, Theis RP, Thompson LA et al (2020) Tobaccorelated counseling and documentation in adolescent primary care practice: challenges and opportunities. Nicotine Tob Res 22:1023-1029. https://doi.org/10.1093/ntr/ntz076

88. Amato MS, Bottcher MM, Cha S et al (2021) "It's really addictive and I'm trapped:" a qualitative analysis of the reasons for quitting vaping among treatment-seeking young people. Addict Behav 112:106599. https://doi.org/10.1016/j.addbeh.2020. 106599

89. Hartmann-Boyce J, McRobbie H, Lindson N et al (2021) Electronic cigarettes for smoking cessation. Cochrane Database Syst Rev. https://doi.org/10.1002/14651858.CD010216.pub5

90. Sanchez S, Kaufman P, Pelletier H et al (2021) Is vaping cessation like smoking cessation? A qualitative study exploring the responses of youth and young adults who vape e-cigarettes. Addict Behav 113:106687. https://doi.org/10.1016/j.addbeh. 2020.106687

91. Cavallo DA, Krishnan-Sarin S (2019) Nicotine use disorders in adolescents. Pediatr Clin North Am 66:1053-1062. https://doi. org/10.1016/j.pcl.2019.08.002

92. Graham AL, Jacobs MA, Amato MS (2020) Engagement and 3 -month outcomes from a digital e-cigarette cessation program in a cohort of 27000 teens and young adults. Nicotine Tob Res 22:859-860. https://doi.org/10.1093/ntr/ntz097

93. Graham AL, Amato MS, Cha S et al (2021) Effectiveness of a vaping cessation text message program among young adult e-cigarette users: a randomized clinical trial. JAMA Intern Med 181:923-930. https://doi.org/10.1001/jamainternmed.2021.1793

94. Al-Hamdani M, Hopkins DB, Park T (2020) Vaping among youth and young adults: a "red alert" state. J Public Health Policy 41:63-69. https://doi.org/10.1057/s41271-019-00193-2

95. Substance Abuse and Mental Health Services Administration (SAMHSA): (2020) Reducing vaping among youth and young adults. SAMHSA Publication No. PEP20-06-01-003.
96. Kosmider L, Sobczak A, Fik M et al (2014) Carbonyl compounds in electronic cigarette vapors: effects of nicotine solvent and battery output voltage. Nicotine Tob Res 16:1319-1326. https://doi. org/10.1093/ntr/ntu078

97. Abeles M, Popofsky S, Wen A et al (2020) Vaping-associated lung injury caused by inhalation of cannabis oil. Pediatr Pulmonol 55:226-228. https://doi.org/10.1002/ppul.24579

98. Jackson DB, Boccio CM, Leal WE, Vaughn MG (2019) It's all the rage! Exploring the nuances in the link between vaping and adolescent delinquency. J Crim Justice 63:58-69. https://doi.org/ 10.1016/j.jcrimjus.2019.04.004

99. Schillo BA, Cuccia AF, Patel M, et al (2020) JUUL in school: teacher and administrator awareness and policies of e-cigarettes and JUUL in U.S. Middle and High Schools. Health Promot Pract 21:20-24. https://doi.org/10.1177/1524839919868222

100. Allem J-P, Dharmapuri L, Unger JB, Cruz TB (2018) Characterizing JUUL-related posts on Twitter. Drug Alcohol Depend 190:1-5. https://doi.org/10.1016/j.drugalcdep.2018.05.018

101. Kavuluru R, Han S, Hahn EJ (2019) On the popularity of the USB flash drive-shaped electronic cigarette Juul. Tob. Control 28:110 112. https://doi.org/10.1136/tobaccocontrol-2018-054259

102. Centers for Disease Control and Prevention (2020) Outbreak of lung injury associated with the use of e-cigarette, or vaping, products. https://www.cdc.gov/tobacco/basic_information/ecigarettes/severe-lung-disease.html. Accessed 3 Mar 2021.

103. Rossheim ME, Livingston MD, Soule EK et al (2019) Electronic cigarette explosion and burn injuries, US Emergency Departments 2015-2017. Tob Control 28:472-474. https://doi.org/10. 1136/tobaccocontrol-2018-054518

104. Kumetz EA, Hurst ND, Cudnik RJ, Rudinsky SL (2016) Electronic cigarette explosion injuries. Am J Emerg Med 34:2252. e1-2252.e3. https://doi.org/10.1016/j.ajem.2016.04.010

105. Cho JH, Shin E, Moon S-S (2011) Electronic-cigarette smoking experience among adolescents. J Adolesc Heal 49:542-546. https://doi.org/10.1016/j.jadohealth.2011.08.001

106. Farsalinos KE, Romagna G, Allifranchini E, et al. Comparison of the cytotoxic potential of cigarette smoke and electronic cigarette vapour extract on cultured myocardial cells. Int J Environ Res Public Health. 2013;10(10):5146-5162.

107. US Department of Health and Human Services. (2021). quitSTART. https://smokefree.gov/tools-tips/apps/quitstart. Accessed 31 July 2021.

Publisher's Note Springer Nature remains neutral with regard to jurisdictional claims in published maps and institutional affiliations. 